\title{
Relación entre el Código Orgánico General de Procesos y el procedimiento arbitral ${ }^{*}$
}

\author{
Alvaro Galindo Cardona ${ }^{* *}$ y Hugo García Larriva ${ }^{* *}$
}

SUMARIO: 1. Acercamiento a la problemática. 2. Relación entre el COGEP y el procedimiento arbitral. 2.1. Autonomía del procedimiento arbitral. 2.2. ¿Un sistema autocontenido? 2.3. Auxilio jurisdiccional. 3. Normas del COGEP aplicables dentro del proceso arbitral por disposición de la LAM. 3.1. Requisitos de la demanda, contestación a la demanda, reconvención y contestación a la reconvención. 3.2. Excusa y recusación de árbitros. 4. Normas del COGEP aplicables dentro del proceso arbitral de manera supletoria. 4.1. Citación con la demanda. 5. Procedimientos del COGEP auxiliares al procedimiento arbitral. 5.1. Diligencias preparatorias. 5.2. Medidas cautelares o providencias preventivas. 5.2.1. Medidas cautelares ordenadas por los jueces ordinarios. 5.2.2. Medidas cautelares ordenadas por los árbitros. 5.3. Homologación de laudos internacionales. 5.4. Ejecución de laudos arbitrales. 6. A manera de conclusiones.

\footnotetext{
${ }^{*}$ Las ideas presentadas en este artículo son reflexiones de los autores, realizadas desde una perspectiva abstracta y con un enfoque puramente académico, por lo que no vinculan a sus estudios jurídicos ni a ninguno de sus clientes. Los autores agradecen los valiosos comentarios de Xavier Andrade, Daniela Páez y Oswaldo Santos que han ayudado a mejorar el contenido de este artículo. Por supuesto, no se debe asumir que ellos están de acuerdo con las opiniones aquí contenidas, ni con nuestra expresión de ellas. Para la fácil incorporación en el texto y posterior consulta, todas las direcciones de páginas de internet han sido acortadas usando la aplicación Google Shortener $<$ https://goo.gl>. De igual manera, todas las direcciones de páginas de internet citadas han sido visitadas por última vez el 4/8/2015.

** Profesor de la Universidad de Georgetown y Director de la Maestría en Litigio Internacional y Arbitraje (MLA) de la Universidad San Francisco de Quito. Consejero Internacional en Dechert LLP (Washington D.C.). Licenciado en Ciencias Jurídicas y Doctor en Jurisprudencia por la Universidad Católica del Ecuador, LL.M. por la Universidad de Georgetown.

*** Profesor y Subdirector de la Maestría en Litigio Internacional y Arbitraje (MLA) de la Universidad San Francisco de Quito. Senior Associate en Corral Rosales Carmigniani Pérez (Quito, Ecuador). Abogado por la Universidad San Francisco de Quito, Especialista Superior en Derecho Procesal por la Universidad Andina Simón Bolívar, Sede Ecuador, Magíster en Derecho de Empresa por la Universidad San Francisco de Quito y LL.M. en Derecho Internacional por la Universidad de Cambridge.
} 


\section{Acercamiento a la problemática}

En un pasaje de la Eneida, Eneas relata a Dido cómo un artilugio con forma de enorme caballo de madera fue usado por los griegos como una estrategia para introducirse en la ciudad fortificada de Troya. Ahí, frente a la invitación de Timetes para llevar el caballo dentro de los muros, el sacerdote Laocoonte advirtió: “¡Troyanos, no creáis en el caballo! ¡Sea de él lo que

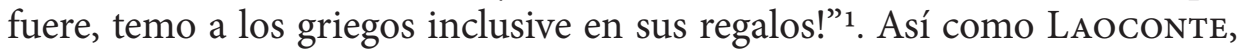
muchos académicos y practicantes del arbitraje han visto en los códigos procesales aquel artilugio por el cual el formalismo, ritualismo y rigidez de la justicia ordinaria viene a destruir la eficiencia, eficacia y flexibilidad del arbitraje. Esto, lamentablemente, ha demostrado ser verdad en no pocos casos.

El 22 de mayo de 2015, el Ecuador estrenó un nuevo Código Orgánico General de Procesos (COGEP) ${ }^{2}$-aunque en una etapa de vacatio legis en la mayor parte de sus disposiciones ${ }^{3}-$. Este código viene a reemplazar el decimonónico Código de Procedimiento Civil y la maraña de leyes procesales que hacían del litigio en las cortes ecuatorianas un verdadero reto profesional y un suplicio para las partes. La falta de simplicidad y el exagerado ritualismo de los procedimientos colaboraron en el agravamiento del problema del congestionamiento de las causas. Frente a esta realidad, el COGEP es un viento fresco en el sistema procesal ecuatoriano. Se simplifican los procedimientos a unos pocos. El COGEP refuerza el sistema de litigio oral basado en audiencias, pero sobre todo permite un litigio moderno. Muchas de sus disposiciones van a tono con la práctica actual del arbitraje, por ejemplo, el uso de videoconferencia en la realización de diligencias (incluso testimoniales) ${ }^{4}$, el uso de mecanismos electrónicos para la recepción de documentos y para la conservación de los archivos ${ }^{5}$, peritos de parte ${ }^{6}$, careo de testigos y peritos ${ }^{7}$, etcétera.

Es en este contexto que resulta relevante el revisar cuál es la relación que guarda el COGEP con el arbitraje. Para estos efectos, por consideraciones de

1. Virgilio, La Eneida, Libresa, 1990, p. 83.

2. Código Orgánico General de Procesos (COGEP), R.O. Supl. No. 506, 22/5/2015.

3. La disposición final segunda del COGEP establece un periodo de vacancia legal de un año para su aplicación. Se exceptúan de esta vacancia legal algunas de sus disposiciones, entre ellas, las que reforman la Ley de Arbitraje y Mediación.

4. COGEP, Arts. 4, 174, 192, Nota 2.

5. COGEP, Arts. 115, 116, 117, 119, 202, Nota 2.

6. COGEP, Arts. 225, 226, Nota 2.

7. COGEP, Art. 222, Nota 2. 
orden metodológico, hemos decidido restringir el objeto de estudio al arbitraje comercial local, salvo en lo que respecta al reconocimiento y ejecución de laudos internacionales y a la ejecución de medidas cautelares ordenadas por tribunales arbitrales internacionales. Así, el presente artículo [2] establecerá un marco teórico general que establece la tesis de este trabajo sobre la relación entre el COGEP y el procedimiento arbitral; luego analizará [3] las normas del COGEP que son directamente aplicables dentro del proceso arbitral por disposición de la LAM, [4] las normas del COGEP aplicables al proceso arbitral de manera supletoria, y, por último, [5] los procedimientos del COGEP que son auxiliares al procedimiento arbitral.

\section{Relación entre el COGEP y el procedimiento arbitral}

La relación entre las normas que rigen los procesos en la justicia ordinaria y las normas que rigen el proceso arbitral no ha sido del todo pacífica ${ }^{8}$. En términos generales, el acercamiento a esta temática ha estado marcado por la visión con la que cada persona se ha aproximado al arbitraje. Así, litigantes que se sienten cómodos con los rituales y procedimientos de la justicia ordinaria, tienden a considerar que la normativa que rige los procesos ordinarios es directamente aplicable a los procedimientos arbitrales. No es poco común entre este grupo que, ante un desvío de la normativa procesal ordinaria, de manera firme y vehemente, se aleguen catástrofes constitucionales y nulidades procesales. Otros, por el contrario, rechazan de manera tajante la aplicación en el arbitraje de la normativa procesal que rige los procedimientos de la justicia ordinaria. Quienes lo ven así son, generalmente, litigantes que han recibido instrucción formal en la materia o que han tenido experiencia o contacto con prácticas internacionales. Muchos otros, guiados por un pragmatismo férreo, se encuentran entre una y otra posición. Admiten grados - mayores o menores- de flexibilidad pero siempre manteniendo un pie en la "seguridad" de los procedimientos ordinarios.

8. Ver C. Coronel Jones, “Arbitraje y Procedimiento”, Iuris Dictio, No. 11, USFQ, 2007, pp. 37-41; F. VIDAL RAMírez, "La supletoriedad de las leyes de arbitraje”, en C. Soto CoAguILA (Dir.), El Arbitraje en el Perú y el Mundo, Instituto Peruano de Arbitraje, 2008, pp. 87-90; J. SANTIESTEVAN DE NORIEGA, "Arbitraje y proceso civil, ¿vecinos distantes?: el debido proceso en sede arbitral", Ius et Veritas, No. 32, 2008, pp. 38-58; A. BULLARD GonZÁlez, “¿Es un arbitraje un juicio?”, en C. Soto CoAguila (Dir.), El Arbitraje en el Perú y el Mundo, Instituto Peruano de Arbitraje, 2008, 145-156. 
En realidad, la relación entre las normas que rigen la justicia ordinaria y las normas que rigen los procedimientos arbitrales no debería ser ni tan complicada ni tan accidentada. Por el contrario, un mejor entendimiento del arbitraje nos llevará a concluir que el procedimiento arbitral en el Ecuador es autónomo aunque no necesariamente autocontenido 9 .

\subsection{Autonomía del procedimiento arbitral}

Es autónomo, pues el procedimiento arbitral tiene una naturaleza negocial con efectos jurisdiccionales ${ }^{10}$ que, en principio, no depende de la normativa procesal de la justicia ordinaria. Así, son las partes las que pueden pactar, directamente o por referencia, las reglas del arbitraje, incluyendo aquellas que regulen la práctica de la prueba ${ }^{11}$. Esta naturaleza le da al arbitraje ciertos tintes de un orden espontáneo. Un orden espontáneo -siguiendo a HAYEK- es un tipo de estructura social a partir de la interacción libre de personas interesadas en su propio bienestar cuya intención no es la de crear un orden ${ }^{12}$. Un orden espontáneo no se crea a partir de la planificación. Nadie lo crea, pero a su vez todos la crean. El arbitraje es, en términos generales, producto de la interacción, que, por oposición al sistema jurisdiccional planificado, crea reglas y mecanismos procesales, con una aparente diversidad de origen, que produce resultados satisfactorios, certeros y predecibles ${ }^{13}$. Aquellas normas que generen previsibilidad, certeza y satisfacción perdurarán y gozarán de determinada opinio necessitatis

9. Por régimen autocontenido nos referimos a un sistema legal cerrado y absolutamente autónomo del resto de normas y ordenamiento jurídico. Ver B. SimmA, "Self-contained regimes", Neetherlands Yearbook of International Law, Vol. 16, 1985, p. 111-136; B. Simma y D. PULKowski, "Of Planets and the Universe: Self-contained Regimes in International Law”, The European Journal of International Law, Vol. 17 (3), 2006, 483-529.

10. "Art. 38.- El arbitraje se sujetará a las normas de procedimiento señaladas en esta Ley, al procedimiento establecido en los centros de arbitraje, al determinado en el convenio arbitral o al que las partes escojan, sin perjuicio de las normas supletorias que sean aplicables". Ley de Arbitraje y Mediación (LAM), R.O. No. 417, 14/12/2006. Ver además, A. SERRANO PUIG, "La autonomía de la voluntad en el convenio arbitral: alcance y limitaciones. El caso ecuatoriano", en C. SoTo (Dir.) Tratado de Derecho Arbitral: El Convenio Arbitral, Tomo I, Instituto Peruano de Arbitraje, 2011, 541-582.

11. Es premisa de este artículo que, en ausencia de acuerdo de las partes sobre un determinado tema procesal, los árbitros pueden decidir qué norma de procedimiento adoptar. Si bien el analizar la fuente de las facultades procesales de los árbitros es un tema importante e interesante, cae fuera del espectro de este artículo. Para efectos del mismo, independiente de la fuente de esta facultad, se asume que tal facultad existe. Ver, C. Coronel, Nota 8, p. 38; F. GonzÁlez de Cossío, El Árbitro, Porrúa, 2008, pp. 43-49.

12. F. A. HAYEK, "Los principios de un orden social liberal", Estudios públicos, No. 6, 1982, p. 179-202; F. SosA VALlE, "El concepto hayekiano de orden espontáneo", Revista de Instituciones, Ideas y Mercados, No. 49, Octubre 2008, pp. 188-191

13. C. CORONEL JONES, Nota 8, p. 37; A. De Jesús y J. R. FerRIS, The New World Order Of Economic Relations In The Light Of Arbitral Jurisprudence, Position paper at the Beaune Meeting, 27/09/2014; A. BULLARD, "El arbitraje nacional en el Proyecto de Reforma de la Ley General de Arbitraje”, en M. CASTILLO FreIRE, Compilación de ponencias del Congreso Internacional de Arbitraje 2007, Tomo 2, Vol. 6, Estudio Mario Castillo Freire, 2008, p. 364. 
en la comunidad arbitral ${ }^{14}$; aquellas que no, serán reemplazadas por otras más eficientes y así sucesivamente ${ }^{15}$. Si entendemos al Derecho como un complejo fenómeno social que incorpora unas reglas últimas de reconocimiento que establecen los criterios por medio de los cuales cada comunidad decide si una determinada regla es parte de su derecho, y admitimos -como lo sostiene HART ${ }^{16}$ - que existen fuentes sociales de Derecho, estas reglas destiladas de la interacción entre individuos de la comunidad arbitral, podrían ser consideradas como normas jurídicas y no como meros usos ${ }^{17}$. Es más, al parecer este es el caso bajo el artículo 38 de la LAM $^{18}$. El que exista un reconocimiento expreso -y por lo tanto autorización- en la ley de la existencia de este proceso de creación espontáneo de reglas implica que, al menos en el Ecuador, este proceso normativo no sucede al margen del ordenamiento jurídico, sino por el contrario, se da dentro y con referencia al mismo. Ahora claro, nada impide que estas normas estén configuradas para no ser vinculantes ${ }^{19}$. Ejemplos de esto hay muchos, entre los cuales podemos

Ver, en general, J. KARTON, The Culture of International Arbitration and The Evolution of Contract Law, Oxford University Press, 2013.

14. Véase, por ejemplo, las recientes reformas normativas en la mayoría de las más importantes instituciones arbitrales para la inclusión del árbitro de emergencia (Corte de Arbitraje de la Cámara de Comercio Internacional, la Corte de Arbitraje Internacional de Londres, el Centro de Arbitraje Internacional de Singapur, el Centro de Arbitraje Internacional de Hong Kong, el Instituto de Arbitraje de la Cámara de Comercio de Estocolmo, entre otros).

15. A. BULLARD presenta una interesante explicación económica sobre este punto: "Si un mercader acepta en su contrato una regla ineficiente o excesivamente costosa, perderá capacidad de competir, pues sus costos de participar en el mercado serán mayores a los de sus competidores que fueron capaces de tener una mejor regla. De la misma manera un comerciante que tiene sus operaciones comerciales sujetas a las cortes ordinarias asumirá los costos que ello implica en relación a otro comerciante que somete todas sus operaciones al arbitraje. El resultado es que el último tendrá una ventaja competitiva sobre el primero, que le permitirá desplazar a su rival en el mercado. Así, se prefiere identificar reglas que imponen menos costos a la actividad económica generando a su vez confianza, lo que a su vez conduce a una uniformización contractual hacia las reglas más eficientes. De la misma manera, como los consumidores escogen productos más baratos y de mejor calidad, los comerciantes escogen reglas baratas de aplicar y adecuadas para el intercambio. Y las reglas del arbitraje, esas que nacen espontáneamente, son reglas baratas y adecuadas para el intercambio". A. Bullard, Nota 13, p. 370.

16. En el positivismo metodológico de HART, para que el derecho exista debe haber alguna forma de práctica social que incluya a los jueces y a los ciudadanos ordinarios, y esta práctica social determina lo que en cualquier sistema jurídico dado son las fuentes últimas del derecho o criterios últimos de validez jurídica. A. HART, "El nuevo desafío al positivismo jurídico", Sistema: Revista de ciencias sociales, No. 36, 1980, p. 5. Los autores no necesariamente se suscriben a la corriente positivista del Derecho, sin embargo la han usado con el fin de demostrar que aun bajo ésta el argumento es válido. Uno podría arribar a la misma conclusión a través del realismo jurídico o alguna otra teoría de Derecho (Ver en general S. RoBIN LETwIN, On the History of the Idea of Law, Cambridge University Press, 2005).

17. Ahora bien, alguien puede válidamente cuestionar la relevancia o no de que las normas procesales en arbitraje sean categorizadas o no como normas jurídicas. De hecho alguien puede abogar por la existencia de sistemas de normas fuera del sistema legal que cumplen la misma -o quizás de mejor manera- función de regular las conductas de los individuos. Ver por ejemplo, L. BERNSTEIN, "Opting out of the Legal System: Extralegal Contractual Relations in The Diamond Industry”, The Journal of Legal Studies, Vol. 21 (1), 1992, pp. 115-157. En general B. L. BENSON, The Enterprise of Law: Justice without the State, The Independent Institute, 2011.

18. LAM, Art. 38, Nota 10.

19. De hecho las reglas no vinculantes pueden estar diseñadas para que su aplicación se dé únicamente por inclusión de las partes (opt in), o que estas se apliquen salvo exclusión de las partes (opt out). 
mencionar a las "Reglas de la International Bar Association (IBA) sobre la Práctica de la Prueba en el Arbitraje Internacional"20, el "Redfern Schedule"21 para la solicitud de exhibición de documentos, el "Reed Schedule/Retreate"22 para las deliberaciones de los tribunales, el "Scott Schedule"23 para la determinación del thema decidendum y posiciones en materia de daños, entre otros ${ }^{24}$.

Recapitulando, el arbitraje, al estar fundamentado en la autonomía de la voluntad, permite que las partes pacten y diseñen reglas que más convengan a su particular relación. Esta interacción entre las partes tiene características similares a las de un orden espontáneo: la ausencia de planificación, de rigidez y de inmutabilidad. Este proceso permite a la comunidad arbitral beneficiarse de reglas predecibles, certeras y eficaces que son susceptibles de mejoramiento y adaptación a nuevas circunstancias. Este proceso espontáneo encuentra reconocimiento en el artículo 38 de la $\mathrm{LAM}^{25}$. Así, por oposición al orden planificado del proceso civil, el proceso arbitral es autónomo y, para preservar esta naturaleza, en principio, las normas procedimentales de los juicios ordinarios no le son aplicables.

\section{2. ¿Un sistema autocontenido?}

Afirmamos que las normas procedimentales no son aplicables al arbitraje "en principio", pues el procedimiento arbitral bajo la legislación ecuatoriana no es necesariamente autocontenido ${ }^{26}$. Por expresa disposición de la LAM, existen determinadas actividades que se rigen por las disposiciones que gobiernan la justicia ordinaria. En ausencia de estas referencias expresas en la misma LAM, el COGEP no es directamente aplicable a los procedimientos arbitrales. El COGEP podría ser aplicado de manera subsidiaria al procedimiento arbitral cuando las partes o los árbitros así lo consideren

20. IBA, Reglas de la International Bar Association (IBA) sobre la Práctica de la Prueba en el Arbitraje Internacional, $<$ http://goo.gl/0IQMkI>.

21. Centro Internacional de Arreglo de Diferencias Relativas a Inversiones (CIADI), Redfern Schedule, <https://goo. gl/aPvDJo $>$.

22. L. REED, The Kaplan Lecture 2012: Arbitral Decision-making: Art, Science or Sport?, <http://goo.gl/OG3ccx>.

23. K\&L Gates y Navigant, Use of the "Scott Schedule" to Expedite the Resolution of Quantum Issues, <http://goo.gl/ $\mathrm{ePkdDd}>$. Es interesante que este esquema haya sido importado al arbitraje del litigio ordinario dentro de las cortes inglesas.

24. Otros ejemplos pueden ser el Sachs Protocol y el Kapaln Opening.

25. LAM, Art. 38, Nota 10.

26. Aunque bien pudiera serlo, sin embargo eso es una discusión sobre cómo la ley debería ser y no cómo la ley es o cómo debería ser interpretada. 
oportuno, siempre y cuando no contravenga la naturaleza del arbitraje ${ }^{27}$. Sin embargo, este último escenario no es distinto del mismo ejercicio de la autonomía de la voluntad que las partes tienen para escoger cualquier otro tipo de norma procesal, salvo que en este caso, la norma escogida-COGEPsería aquella que naturalmente no pertenece al arbitraje.

\subsection{Auxilio jurisdiccional}

El COGEP y el arbitraje también guardan otro tipo de relación. Nos referimos a los procedimientos que son auxiliares al procedimiento arbitral. En este caso ya no nos preguntamos por aquellas disposiciones del COGEP que le son aplicables al arbitraje, sino por aquellas disposiciones que sirven de complemento o auxilio al procedimiento arbitral. Algunas de ellas son, por ejemplo, la ejecución de laudos arbitrales y medidas cautelares, o la homologación de laudos internacionales.

Así, como conclusión general sobre la relación entre el COGEP y el procedimiento arbitral, podemos decir que: [1] el procedimiento arbitral es autónomo y se rige por la voluntad de las partes, y, en consecuencia de lo anterior, [2] el COGEP no se aplica directamente al arbitraje, [3] salvo en aquellos casos en los cuales la LAM hace expresa referencia al mismo. De igual manera, [4] el COGEP establece algunos procedimientos que sirven de auxilio jurisdiccional a los procedimientos arbitrales.

\section{Normas del COGEP aplicables dentro del proceso arbitral por dis- posición de la LAM}

Como se explicó anteriormente, la relación entre el COGEP y la LAM gira en torno a aquellas disposiciones del primero, que, por expreso mandato de la segunda, le son aplicables al proceso arbitral ${ }^{28}$, como son [3.1.] los requi-

27. Un interesante reflejo de este principio lo encontramos en el artículo 52 del Reglamento para el Funcionamiento del Centro de Arbitraje y Mediación de la Cámara de Comercio Ecuatoriano Americana (Reglamento AMCHAM) <http://goo.gl/FmYhUI>: "Art. 52.- Las normas de procedimiento que rijan el arbitraje ante este Centro serán las señaladas en la Ley de Arbitraje y Mediación, las establecidas en el presente reglamento y supletoriamente, en lo que no contravenga las normas y principios del arbitraje, las del Código de Procedimiento Civil, y en este último caso, en los procesos en Derecho".

28. Conforme a lo dispuesto por la Disposición Reformatoria Primera del COGEP, toda referencia hecha al Código de Procedimiento Civil (CPC) debe entenderse hecha al COGEP, una vez que éste entre en vigencia. Como se mencionó supra, las normas del COGEP que modifican a la LAM están en vigencia desde su publicación en el Registro Oficial. 
sitos que deben observar la demanda, contestación a la demanda, reconvención y contestación a la misma; y, [3.2.] las causales y procedimiento de excusa y recusación de los árbitros.

\subsection{Requisitos de la demanda, contestación a la demanda, reconvención y contestación a la reconvención}

Una característica peculiar del arbitraje administrado ecuatoriano es que contempla dos etapas procesales: una previa que se sustancia ante el Director del centro de arbitraje y una posterior que se desarrolla ante el tribunal arbitral. Esta división ha traído algunas complicaciones y preguntas que, generalmente, están relacionadas con la naturaleza jurídica de las funciones de un director de un centro de arbitraje ${ }^{29}$. Al margen de esta discusión, una de las facultades más importantes que tiene el director de un centro es la de recibir y calificar tanto la demanda y la reconvención como sus respectivas contestaciones ${ }^{30}$. En contraste, para el caso de arbitrajes independientes, serán los árbitros seleccionados por las partes aquellos que llevarán a cabo esta misma función ${ }^{31}$. Así, lo primero que deben hacer, tanto el director del centro de arbitraje como los árbitros independientes, es verificar que la demanda, la contestación a la demanda, la reconvención y la contestación a ésta, cumplan con los requisitos establecidos en el artículo 10 de la LAM.

De manera residual, la LAM también exige que la demanda cumpla con los demás requisitos que la ley exija para cada caso y que, además, se cumplan con los requisitos señalados en el artículo 142 del COGEP. Muchos de los requisitos establecidos en esta norma coinciden con los enumerados en el artículo 10 de la LAM, por lo que sólo mencionaremos aquellos que se adicionan. Estos son:

29. La doctrina que ha analizado el tema ha concluido que, por la naturaleza y efectos de sus actos, los directores ejercen jurisdicción limitada, conocida como "jurisdicción de sustanciación”. A diferencia de Colombia donde fue declarada inconstitucional esta facultad de los directores por haber la constitución colombiana otorgado jurisdicción únicamente a los árbitros -Corte Constitucional de Colombia, Sentencia C 1038 expedida el 28 de noviembre de 2002, <http://goo.gl/0n5P98>-, en Ecuador constitucionalmente se reconoce al arbitraje conforme las disposiciones de la Ley, y ésta otorga esas facultad a los directores de los centros. Ver J. F. GUERRERO, “Caben las medidas cautelares constitucionales en contra de un proceso arbitral?”, Revista Ecuatoriana de Arbitraje 2011, Instituto Ecuatoriano de Arbitraje, 2012, pp. 113-126.

30. "Art. 10.- La demanda se presentará ante el director del centro de arbitraje correspondiente o ante el árbitro o árbitros independientes que se hubieren establecido en el convenio [...]”; "Art. 11.- Presentada la demanda, el director del centro de arbitraje, o si fuere el caso, el árbitro o árbitros independientes previa su posesión conforme lo establecido en el artículo 17, calificarán la demanda [...]”. LAM, Arts. 10 y 11, Nota 10.

31. Ibídem. 
1. Se debe indicar los nombres y apellidos completos, número de cédula de identidad o ciudadanía, pasaporte, estado civil, edad, profesión u ocupación, dirección domiciliaria y electrónica de la o del actor, casillero judicial o electrónico de su defensora o defensor público o privado. Cuando se actúa en calidad de procuradora o procurador o representante legal se hará constar también los datos de la o del representado.

2. Se debe indicar la dirección electrónica donde se deba citar al demandado, si se conoce.

3. Se debe acompañar la nómina de testigos con indicación de los hechos sobre los cuales declararán y la especificación de los objetos sobre los que versarán las diligencias probatorias, tales como la inspección judicial, la exhibición, los informes de peritos $^{32} \mathrm{y}$ otras similares.

4. Si no tiene acceso a las pruebas documentales o periciales, se describirá su contenido, con indicaciones precisas sobre el lugar en que se encuentran y la solicitud de medidas pertinentes para su práctica.

Ahora, con referencia a la calificación de la demanda y reconvención, un tema que particularmente ha generado problemas ha sido la determinación de la cuantía -con su correspondiente consecuencia en los costos del arbitraje-. En la práctica se cometen muchos errores al instante de determinar la cuantía, algunos de ellos con fatales consecuencias al momento de resolver la causa. El artículo 144 del COGEP trae algunas luces al respecto -que existían ya desde el anterior código-. El artículo establece que para la determinación de la cuantía se deberán observar las siguientes reglas:

1. Se deberán tomar en cuenta los intereses líquidos del capital, los que estén pactados en el documento con que se proponga la demanda y los frutos que se han liquidado antes de proponerla.

32. Este es un cambio sustancial, pues implica que el sistema ha cambiado de peritos del tribunal a peritos de parte, $y$, en efecto, estos informes ahora deben prepararse con anterioridad a la demanda y deben ser adjuntados a la misma. 
2. Cuando la demanda verse sobre derechos de valor indeterminado que se refieran a cosas susceptibles de apreciación, se fijará la cuantía atendiendo el precio de las cosas.

3. En los procesos provenientes de arrendamiento, la cuantía se determinará por el importe de la pensión de un año o por lo que valga en el tiempo estipulado, si este es menor.

4. En materia laboral se cuantificará cada una de las pretensiones de la o del actor para establecer la cuantía.

5. La cuantía será indeterminada únicamente cuando trate de asuntos no apreciables en dinero o que no se encuentren previstos en los casos anteriores.

Otro tema donde se debe tener especial atención es el registro que dispone el párrafo quinto del artículo146 del COGEP. Este artículo dispone que, antes de citar al demandado, se debe realizar la "inscripción en el registro correspondiente, de las demandas (léase también reconvenciones) que versen sobre dominio o posesión de inmuebles o de muebles sujetos a registro, así como también de las demandas que versen sobre demarcación y linderos, servidumbres, expropiación, división de bienes comunes y acciones reales inmobiliarias" 33 .

Por otro lado, en lo que respecta a la contestación a la demanda $-y$, por extensión, la contestación a la reconvención- el artículo 11 de la LAM establece que ésta debe cumplir con los requisitos establecidos en el artículo 151 del COGEP, que a su vez se remite al artículo 144 del mismo cuerpo normativo donde constan los requisitos de la demanda. Adicionalmente, la contestación a la demanda deberá contener un pronunciamiento expreso sobre cada una de las pretensiones de la parte actora, sobre la veracidad de los hechos alegados en la demanda y sobre la autenticidad de la prueba documental que se haya acompañado, con la indicación categórica de lo que admite y de lo que niega ${ }^{34}$. Deberán además incluirse todas las excepciones contra las pretensiones de la parte actora, con expresión de su fundamento fáctico ${ }^{35}$.

33. COGEP, Art. 146, Nota 2.

34. COGEP, Art. 151, Nota 2.

35. Ibídem. 


\subsection{Excusa y recusación de árbitros}

En la actualidad muy pocas personas se atreverían a disputar que parte del derecho a la debida defensa incluye el de ser juzgado por un juez independiente e imparcial ${ }^{36}$. Mucho se ha dicho sobre el alcance de estas definiciones y su contenido ${ }^{37} \mathrm{y}$, por más atractivo que resulte el tema, éste excede los objetivos de este artículo. Este acápite, entonces, se centra en los mecanismos que prevé la legislación ecuatoriana para la defensa de este derecho, es decir, la excusa y la recusación de los árbitros. Al respecto, el artículo 21 de la LAM establece que son causas de recusación y excusa de los árbitros aquellas previstas para los jueces ${ }^{38}$. Así, la LAM nos refiere al artículo 22 del COGEP ${ }^{39}$ que dispone que los juzgadores pueden excusarse o ser recusados por las siguientes causas:

1. Ser parte en el proceso.

2. Ser cónyuge o conviviente en unión de hecho de una de las partes o su defensora o defensor.

3. Ser pariente hasta el cuarto grado de consanguinidad o segundo de afinidad de alguna de las partes, de su representante legal, mandatario, procurador, defensor o de la o del juzgador de quien proviene la resolución que conoce por alguno de los medios de impugnación.

4. Haber conocido o fallado en otra instancia y en el mismo proceso la cuestión que se ventila u otra conexa con ella.

36. "Art. 76.- En todo proceso en el que se determinen derechos y obligaciones de cualquier orden, se asegurará el derecho al debido proceso que incluirá las siguientes garantías básicas: [... 7. El derecho de las personas a la defensa incluirá las siguientes garantías: [...] k) Ser juzgado por una jueza o juez independiente, imparcial y competente. [...]”. Constitución del Ecuador, Art. 76(7)(k), R.O. No. 449, 20/10/2008.

37. Por ejemplo, R. JIJÓN LETORT, "La independencia e imparcialidad de los árbitros”, Iuris Dictio, No. 11, 2007, pp. 26-36; F. GONZÁLEZ DE Cossío, "Independencia, imparcialidad y apariencia de imparcialidad de los árbitros", Jurídica: Anuario del Departamento de Derecho de la Universidad Iberoamericana, No. 32, 2002, pp. 459-479; C. LEPERVANCHE M., "Algunos apuntes sobre la independencia e imparcialidad de los árbitros en el arbitraje comercial”, Spain Arbitration Review: Revista del Club Español del Arbitraje, No. 12, 2011, pp. 25-55; L. M. ESCOBAR MARTÍNEZ, "La independencia, imparcialidad y conflicto de interés del árbitro”, International Law: Revista Colombiana de Derecho Internacional, No. 15, 2009, pp. 181-214; F. DE TRAZEGNIES GrANDA, "Conflictuando el conflicto. Los conflictos de interés en el arbitraje", Lima Arbitration: Revista del Círculo Peruano de Arbitraje, No. 1, 2006, pp. 163-184. En general, S. LuTTRELL, Bias Challenges in International Commercial Arbitration: The need for a 'real danger' test, Wolters Kluwer, 2009.

38. LAM, Art. 21, Nota 10.

39. COGEP, Art. 22, Nota 2. 
5. Retardar de manera injustificada el despacho de los asuntos sometidos a su competencia. Si se trata de la resolución, se estará a lo dispuesto en el Código Orgánico de la Función Judicial.

6. Haber sido representante legal, mandatario, procurador, defensor, apoderado de alguna de las partes en el proceso actualmente sometido a su conocimiento o haber intervenido como mediador.

7. Haber manifestado opinión o consejo que sea demostrable, sobre el proceso que llega a su conocimiento.

8. Tener o haber tenido ella, él, su cónyuge, conviviente o alguno de sus parientes hasta el cuarto grado de consanguinidad o segundo de afinidad con alguna de las partes. Cuando el proceso haya sido promovido por alguna de las partes, deberá haberlo sido antes de la instancia en que se intenta la recusación.

9. Haber recibido de alguna de las partes derechos, contribuciones, bienes, valores o servicios.

10. Tener con alguna de las partes o sus defensores alguna obligación pendiente.

11. Tener con alguna de las partes o sus defensores amistad íntima o enemistad manifiesta.

12. Tener interés personal en el proceso por tratarse de sus negocios o de su cónyuge o conviviente, o de sus parientes dentro del cuarto grado de consanguinidad o segundo de afinidad.

Las causales 1, 2, 3, 6, $7^{40}, 12$ no traen, en términos generales, mayores problemas. Sin embargo, existen ciertas causales cuya aplicación al arbitraje produce, al menos teóricamente, algunas dificultades.

40. No debe confundirse esta causal -“[h]aber manifestado opinión o consejo [...] sobre el proceso que llega a su conocimiento"- con la causal conocida como conflicto objetivo de intereses -haber expresado una opinión sobre los temas que subyacen al proceso, sin haberse referido expresamente al proceso, causal que, por lo demás, es ampliamente discutida como una real fuente de conflicto de intereses. Ver F. GoNZÁLEZ DE Cossío, Nota 11, 
Por ejemplo, la causal enunciada en el numeral cuarto, particularmente en lo referente al haber conocido o fallado cuestiones conexas con la causa principal, ¿qué pasaría si las partes deciden designar a un mismo tribunal que ya conoció un arbitraje para que conozca un nuevo proceso arbitral que surge de un contrato coligado? $\mathrm{O}$ si las partes designan al mismo tribunal arbitral para que conozca un nuevo conflicto sobre un mismo contrato, ¿el tribunal estaría impedido de hacerlo?

De igual manera, las hipótesis 8 y 10 del mismo artículo nos traen otro problema. El numeral octavo prevé el caso en el cual el árbitro -más ciertas personas relacionadas a él- tenga o haya tenido un proceso con alguna de las partes; $y$, por su parte, el numeral décimo prevé el caso en el cual el árbitro tenga una obligación pendiente con una de las partes. Supongamos que un árbitro es designado en un caso de incumplimiento contractual, digamos de construcción de obra, donde una de las partes es un municipio; y supongamos que ese mismo árbitro tiene una obligación tributaria pendiente con ese municipio y que está impugnando otra en sede judicial; en base a estos hechos, ¿perdió el árbitro su imparcialidad para juzgar un incumplimiento contractual que deviene de un contrato de construcción de obra?

En esta misma línea, la situación prevista en la causal novena es aun más compleja. La hipótesis normada por el artículo se refiere al hecho de que el árbitro haya recibido de alguna de las partes derechos, contribuciones, bienes, valores o servicios. El problema es evidente, las partes pagan por los servicios de los árbitros, por lo que ellos, consecuentemente, reciben contribuciones o bienes de las partes. ¿Sería posible, por este hecho, recusar a los árbitros? Asimismo, ad absurdum, hipotéticamente ningún árbitro podría ser designado en un caso donde una parte sea un proveedor de servicios públicos del cual el árbitro sea abonado, sin que éste esté incurso en la causal descrita.

En términos generales, pareciese que es impropio a la naturaleza del arbitraje establecer una valoración abstracta y a priori de estas circunstancias, presumiendo que ellas entrañan una falta de imparcialidad e indepen-

pp. 72-76; D. H. Hranitzky y E. Silva Romero, “The 'Double Hat' debate in international arbitration”, New York Law Journal, 14/6/2010; J. LEVINE, "Dealing with Arbitrator 'Issue Conflicts' in international arbitration”, Transnational Dispute Management, No. 4, 2008. En general ver S. LUTTRELL, Nota 37. 
dencia de los árbitros per se, sin tener debida cuenta de los hechos específicos del caso en particular. Las causales de recusación antes comentadas del COGEP, deben pasar por un proceso de adaptación al proceso arbitral, con miras a garantizar el derecho a un juez independiente e imparcial ${ }^{41}$.

Como último punto sobre las causales aplicables a la recusación y excusa de los árbitros, dos preguntas quedan por ser respondidas. Primero, ¿pueden las partes directamente o por referencia a un reglamento de arbitraje pactar otras causales que no sean las del COGEP? Segundo, ¿pueden las partes renunciar a recusar a un árbitro por una determinada causal? Pareciese que la primera pregunta es más fácil de responder que la segunda, pero, más allá de consideraciones doctrinales, queda aún por ver cómo se pronuncian los árbitros o directores de centros al respecto ${ }^{42}$.

Finalmente, nos queda por mencionar que, si bien las causales del COGEP son, en principio, aplicables a la excusa y recusación de los árbitros, el procedimiento establecido por esta misma norma para el trámite de estos procedimientos no le es directamente aplicable. En este sentido, bien pueden los centros de arbitraje normar este procedimiento de manera diferente ${ }^{43} \mathrm{o}$, en ausencia de esta normativa, las partes o los árbitros pueden recurrir al procedimiento previsto en el COGEP u otra normativa.

41. Un interesante caso es el de la Recusación al Árbitro Santiago Cuesta donde el tribunal que debía resolver su recusación hizo un ejercicio parecido. Caso Chaparro c. Ecuador: Laudo final y Recusación de Santiago Cuesta, en H. García LARriva, Gaceta arbitral, No. 1, 2013. Otro interesante ejemplo lo encontramos en el Art. 72 del Reglamento de AMCHAM que establece que "[c]ualquier árbitro podrá ser recusado de conformidad con lo establecido en el presente Reglamento, la Ley de Arbitraje y Mediación y el Código de Procedimiento Civil en cuanto sus disposiciones le fueren aplicables". Reglamento AMCHAM, Art. 72, Nota 27. Sobre esta disposición es interesante ver lo que resolvió la Directora del Centro de Arbitraje y Mediación de Amcham Quito. En referencia a la causal 10 del artículo 856 del CPCP, ella sostuvo que "[...] a esta Dirección le resulta al menos difícil de concebir cómo esta causal puede ser aplicable dentro de un proceso arbitral [...] Un supuesto fenecimiento del encargo arbitral [por vencimiento del término para dictar el laudo] difícilmente podría producir la recusación del [árbitro], pues su efecto se acerca más a la pérdida de la calidad de árbitro [...]”. Recusación en contra de los árbitros Patrick Barrera Sweeney, Alfredo Corral Borrero y Sasha Madakovic Falconí, Proceso Arbitral No. 4-13, Centro de Arbitraje y Mediación de la Cámara de Comercio Ecuatoriano Americana, Decisión de 27 de marzo de 2014.

42. Según el Art. 21 de la LAM las autoridades que resuelven las recusaciones presentadas en contra de los árbitros son el director del centro o los árbitros no comprendidos en la recusación, dependiendo del caso. LAM, Art. 21, Nota 10.

43. Un interesante ejemplo lo encontramos en la Sección II, Capítulo IV del Reglamento de AMCHAM. Reglamento AMCHAM, Nota 27. 


\section{Normas del COGEP aplicables dentro del proceso arbitral de manera supletoria}

Habíamos establecido antes que el COGEP podría ser aplicado de manera subsidiaria al procedimiento arbitral cuando las partes o lo árbitros así lo consideren oportuno, siempre y cuando no contravenga la naturaleza del arbitraje. También habíamos advertido que este escenario no es distinto del mismo ejercicio de la autonomía de la voluntad que las partes tienen para escoger cualquier otro tipo de norma procesal, salvo que en este caso, la norma escogida sería aquella que naturalmente no le pertenece. En este sentido, el análisis sobre qué normas del sistema ordinario podrían aplicarse supletoriamente al procedimiento arbitral sería infructuoso pues todo dependerá ulteriormente de las partes y del tribunal arbitral.

Sin desmedro de lo anterior, hay una actividad procesal que merece ser analizada. Nos referimos a la citación con la demanda por dos motivos importantes. En primer lugar, la jurisprudencia en materia de nulidad de laudos arbitrales ha entendido que la citación debe realizarse de conformidad con las normas del sistema ordinario por ser normas supletorias a la $\mathrm{LAM}^{44} \mathrm{y}$, siendo la falta de citación una causal de nulidad de los laudos dentro del sistema ecuatoriano, esta interpretación de las cortes resulta extremadamente importante. En segundo lugar, es práctica unánime en el sistema arbitral ecuatoriano realizar esta diligencia con arreglo a lo dispuesto en las normas del sistema ordinario. Por estos motivos, a continuación analizaremos las normas sobre citación que trae el COGEP.

\subsection{Citación con la demanda}

En términos generales, el COGEP establece las mismas reglas que el $\mathrm{CPC}$ en materia de citación. Mantiene los tres medios de citación, i.e., en persona, por boletas o por medios de comunicación. En el segundo se han registrado ligeros cambios, y en el tercero se ha implementado un nuevo medio. La citación en persona se la puede realizar en cualquier lugar, día y hora ${ }^{45}$. La citación por boletas a una persona natural se podrá realizar únicamente

44. Presidencia de la Corte Superior de Pichincha, Diseños Integrales de Telecomunicaciones DITELECOM Cía. Ltda. c. Víctor Fabián Morales Collahuazo, Sentencia de nulidad de laudo arbitral de 23/1/2008.

45. COGEP, Art. 54, Nota 2. 
a través de un familiar del demandado y ya no con una persona del servicio ${ }^{46}$. Sobre la citación a través de medios de comunicación, además de la citación por la prensa ${ }^{47}$, el COGEP ahora incluye la modalidad de citación por una radiodifusora.

Con respecto a la citación por los medios, el COGEP mantiene el requisito que el actor debe realizar la solicitud bajo juramento ${ }^{48}$, pero añade que además se deberá presentar "la certificación del Ministerio de Relaciones Exteriores que indique si la persona salió del país o consta en el registro consular" ${ }^{49}$.

El COGEP también trae normas específicas para la citación de ciertas personas determinadas, como por ejemplo, los ecuatorianos en el exterior ${ }^{50}$, los herederos ${ }^{51}$, las comunidades indígenas, afroecuatorianas, montubias y campesinas no organizadas como personas jurídicas ${ }^{52}$, organismos o instituciones estatales ${ }^{53}$, y agentes diplomáticos ${ }^{54}$.

Por último, el COGEP trae una interesante flexibilización en materia de citación en lo referente a la determinación del lugar donde debe practicarse la diligencia. El artículo 62 del COGEP establece que "[l]a existencia de defectos puramente formales, fácilmente subsanables o que no afecten la determinación del lugar para realizar el acto no serán obstáculo para la citación”55.

\section{Procedimientos del COGEP auxiliares al procedimiento arbitral}

Como lo habíamos mencionado antes, el COGEP y el arbitraje también guardan otro tipo de relación: el auxilio jurisdiccional al arbitraje. Este escenario comprende aquellas disposiciones que sirven de complemento o

46. COGEP, Art. 55, Nota 2.

47. COGEP, Art. 56(1), Nota 2.

48. COGEP, Art. 56, segundo párrafo, Nota 2. Esta disposición trae el interesante dilema de si este juramento puede -y debe- hacérselo ante el director del centro -todo apunta a que sí, hecho que aportaría a la naturaleza jurisdiccional de algunas sus funciones-, o si se podría hacerlo con un escrito declarando bajo juramento.

49. Id., tercer párrafo.

50. COGEP, Art. 57, Nota 2.

51. COGEP, Art. 58, Nota 2.

52. COGEP, Art. 59, Nota 2.

53. COGEP, Art. 60, Nota 2. Por la relevancia y frecuencia con la que este escenario se produce en arbitraje es menester transcribir la norma completa: "Las citaciones a las instituciones del Estado y sus funcionarios por asuntos propios de su empleo, se realizarán en la dependencia local más próxima al lugar del proceso. Para el caso de la citación al Procurador General del Estado se procederá conforme con la ley" (énfasis añadido).

54. COGEP, Art. 61, Nota 2.

55. COGEP, Art. 62, Nota 2. 
auxilio al procedimiento arbitral. Estas pueden ser subsidiarias (si no existe un tribunal arbitral) o complementarias (si la actividad jurisdiccional es necesaria para la obtención del resultado de la actuación arbitral). Nos referimos concretamente a [5.1.] los actos preparatorios; [5.2.] la expedición y ejecución de medidas cautelares o providencias preventivas; [5.3.] la homologación de laudos internacionales; y, [5.4.] la ejecución de laudos arbitrales.

\subsection{Diligencias preparatorias}

La complejidad y particularidad de algunos casos puede exigir que, antes de constituirse un tribunal arbitral, un demandante requiera realizar determinados actos procesales con el fin de constituir o preservar pruebas que, de otra forma, no podrían llegar a presentarse dentro del procedimiento arbitral. Frente a este tipo de circunstancias, y dado el tiempo que puede tomar la constitución de un tribunal arbitral, la justicia ordinaria juega un rol fundamental de auxilio al proceso arbitral ${ }^{56}$.

En este sentido, el artículo 120 del COGEP establece que una persona podrá solicitar una diligencia preparatoria con el fin de [1] determinar o completar la legitimación activa o pasiva de las partes en un futuro proceso; y, [2] anticipar la práctica de prueba urgente que pudiera perderse ${ }^{57}$.

La petición de diligencia preparatoria tiene que indicar los nombres, apellidos y domicilio de las personas contra quien se promoverá la diligencia, el objeto de la misma y la finalidad concreta del acto solicitado ${ }^{58}$. La diligencia, una vez que la petición ha sido calificada por el juez competente, se efectuará con previa citación a la persona contra la cual se la promueve, quien podrá oponerse o solicitar que ésta se modifique o se amplíe ${ }^{59}$.

56. Ver por ejemplo, GANDÍA SELLENS y BLANCO GARCÍA, "La asistencia judicial en el arbitraje comercial internacional en EEUU ¿una nueva oportunidad?”, Arbitraje: Revista de arbitraje comercial y de inversiones, Vol. 6 (1), 2013, pp. 111-155; A. M. ARRARTE ARISNABARRETA, "De la interrelación a la interferencia del poder judicial en los procesos arbitrales: límites de su actuación", Themis Revista de Derecho, No. 53, 2007, p. 99.

57. COGEP, Art. 120, Nota 2. Evidentemente, el último párrafo del artículo que establece la competencia para conocer el juicio posterior en el juez que conoció la diligencia preparatoria, no es aplicable al arbitraje, pues será el árbitro designado de conformidad con el acuerdo de las partes, el competente para conocer la controversia.

58. COGEP, Art. 121, Nota 2.

59. Ibídem. 
Finalmente, de conformidad con el artículo 122 del COGEP ${ }^{60}$, las medidas preparatorias que se pueden solicitar $-\mathrm{y}$ que son relevantes para el arbitraje- son las siguientes:

1. La exhibición de la cosa mueble que se pretende reivindicar o sobre la que se practicará secuestro o embargo; la de los libros de comercio cuando corresponda y demás documentos pertenecientes al comerciante individual, la sociedad, comunidad o asociación; exhibiciónde los documentos necesarios para la rendición de cuentas por quien se halle legalmente obligado a rendirlas; $y$, en general, la exhibición de documentos en los casos previstos en el COGEP.

2. La exhibición de los títulos u otros instrumentos referentes a la cosa vendida, por parte de su enajenante en caso de evicción o pretensiones similares.

3. El reconocimiento de un documento privado.

4. El nombramiento de guardadora o guardador o en los casos de herencia yacente, bienes de la persona ausente y de la o del deudor que se oculta.

5. La apertura de cajas o casilleros de seguridad en las instituciones del sistema financiero.

6. La inspección preparatoria si la cosa puede alterarse o perderse.

7. La recepción de las declaraciones urgentes de las personas que, por su avanzada edad o grave enfermedad se tema fundadamente puedan fallecer o de quienes estén próximos a ausentarse del país en forma permanente o por un largo período.

\subsection{Medidas cautelares o providencias preventivas}

Se entiende por medidas cautelares o preventivas a aquellas tendientes a asegurar los bienes materia del proceso o garantizar el resultado de

60. COGEP, Art. 122, Nota 2. 
éste $^{61}$. En nuestro sistema arbitral la facultad para dictar medidas cautelares se encuentra compartida entre los árbitros y los jueces ordinarios, lo que no significa que ellos puedan ejercerla de manera concurrente ${ }^{62}$. En este sentido, mientras exista un tribunal arbitral, éste es el único competente para dictar medidas cautelares; consecuentemente, los jueces ordinarios sólo podrán ordenar las mismas antes de la constitución del tribunal arbitral o después de que estos hayan dictado su laudo ${ }^{63}$. Siguiendo esta lógica, analizaremos la normativa del COGEP aplicable a las medidas cautelares en dos escenarios, [5.2.1.] cuando son ordenadas por los jueces ordinarios, y [5.2.2.] cuando son ordenadas por los árbitros.

\subsubsection{Medidas cautelares ordenadas por los jueces ordinarios}

Como ya se enunció anteriormente, una parte podría acudir ante un juez ordinario de primera instancia con una solicitud de medidas cautelares en dos escenarios, i.e., antes que se constituya el tribunal arbitral y una vez que éste haya cesado en sus funciones. Para estos fines, el artículo 125 del COGEP requiere que el solicitante pruebe [1] la existencia del crédito y [2] que los bienes del deudor se encuentren en tal estado, que no alcancen a cubrir la deuda o que pueden desaparecer u ocultarse o que el deudor trate de enajenarlos.

Ahora, no es del todo claro qué tipo de medidas cautelares puede dictar el juez ordinario. Primero, es indiscutible que puede ordenar aquellas previstas en el COGEP, esto es, prohibición de enajenar bienes inmuebles ${ }^{64}$, secuestro de bienes y frutos -cuando se tema su deterioro ${ }^{65}$-, la retención de rentas, créditos o bienes que tenga el deudor en poder de un tercero ${ }^{66} \mathrm{y}$

61. LAM, Art. 9, Nota 10.

62. A. Ponce Martínez, "Ejecución de medidas provisionales: interacción entre árbitros y jueces", Boletín Arbitral Amcham Quito, No. 4, 28/9/2012, p. 4, <http://goo.gl/kFvqF9>; E. SALCEDO VERDUGA, Las medidas cautelares en el arbitraje, Volumen 3, Biblioteca de autores de la Facultad de Jurisprudencia de la Universidad Católica de Guayaquil, 2006, p. 90. Curiosamente este autor afirma que en el Ecuador la competencia es concurrente cuando realmente explica el fenómeno como el de jurisdicción compartida (p. 90). Esto se ratifica cuando páginas antes define a la jurisdicción compartida como aquella donde los árbitros y jueces tiene competencia para dictar medidas cautelares pero en momentos determinados y distintos, y a la jurisdicción concurrente como aquella en la cual, simultáneamente, tanto árbitros como jueces pueden ordenar medidas cautelares (pp. 86-88).

63. A. PONCE MartíneZ, Nota 63, p. 4; E. SAlCEdo Verduga, Nota 63, pp. 87-88.

64. COGEP, Art. 126, Nota 2.

65. COGEP, Art. 129, Nota 2.

66. COGEP, Art. 130, Nota 2. 
arraigo del deudor ${ }^{67}$. Segundo, como veremos más adelante, la LAM establece que los árbitros, además de las medidas cautelares que prevé el COGEP, pueden ordenar aquellas que se consideren necesarias para cada caso ${ }^{68}$. En este sentido, cabe preguntarse si, por extensión y por tratarse de medidas que finalmente repercutirán en el arbitraje, los jueces ordinarios pueden también dictar aquellas medidas cautelares que consideren necesarias para cada caso aunque no estén contempladas en el COGEP. Al respecto PonCE MARTínez sostiene que,

En virtud de la existencia de cláusula arbitral, debe entenderse que tales jueces no sólo están autorizados para ordenar las medidas provisionales previstas en el (COGEP) [secuestro, retención, prohibición de enajenar bienes raíces y prohibición de ausentarse del país para extranjeros que carezcan de bienes raíces en el Ecuador], y las previstas en leyes especiales como la Propiedad Intelectual, sino aquellas que pueden ser necesarias para el cumplimiento del arbitraje por iniciarse, como la de mantener el status quo o la de preservar las pruebas o las que permitan garantizar los resultados del proceso ${ }^{69}$.

Si bien es cierto que el argumento expuesto por el autor resulta novedoso, no queda claro por qué de la existencia de un convenio arbitral -cuyo objeto es dar competencia a los árbitros para conocer una controversia- un juez ordinario - cuya competencia depende exclusivamente de la leyadquiere una facultad que de lo contrario no la tuviese. Será interesante ver cómo se pronunciarán -si no lo han hecho ya- las cortes con respecto a este tema.

Por último, es importante destacar dos asuntos. Primero, el que una parte acuda ante un juez ordinario a solicitar una medida cautelar de manera previa a la constitución de un tribunal arbitral, no implica que ésta haya renunciado al convenio arbitral ${ }^{70}$. Segundo, si una parte ha obtenido una me-

67. COGEP, Art. 131, Nota 2 .

68. LAM, Art. 9, Nota 10.

69. A. PonCE MARTíneZ, Nota 63, p. 4.

70. Esto se puede inferir del texto del Art. 9 de la LAM “[...] cualquiera de las partes podrá solicitar a los jueces ordinarios que ordenen la ejecución de estas medidas [...] sin que esto signifique renuncia al convenio arbitral”. LAM, Art. 9, Nota 10. El Art. 58 del Reglamento AMCHAM es muy claro al establecer que "[...] [1]as partes podrán, antes de la conformación del tribunal arbitral y, en circunstancias apropiadas, solicitar a cualquier autoridad judicial competente la adopción de medidas cautelares. La solicitud que una parte haga a una autoridad judicial con el fin de obtener tales medidas no contraviene el convenio arbitral ni constituye una renuncia a éste, y no afecta la competencia y los poderes del tribunal arbitral al respecto". Reglamento AMCHAM, Art. 58, Nota 27. 
dida preventiva antes de iniciar el proceso arbitral, ésta deberá iniciarlo dentro de los 15 días subsiguientes a la expedición de la orden, pues, de lo contrario, las medidas cautelares caducarán y la parte solicitante será responsable de los daños y perjuicios que se pudiesen generar ${ }^{71}$.

\subsubsection{Medidas cautelares ordenadas por los árbitros}

No cabe duda que, en nuestro sistema, los árbitros tiene la facultad para dictar medidas cautelares ${ }^{72}$. Y también es claro que, si las partes lo autorizan, los árbitros pueden ejecutar directamente las medias cautelares que ellos ordenen ${ }^{73}$. En estos dos casos, salvo la referencia discrecional sobre la posibilidad de ordenar las medidas cautelares enumeradas en el COGEP, este cuerpo normativo no tiene relevancia.

La relevancia del COGEP la vamos a encontrar en el caso en cual los árbitros no se encuentren habilitados por las partes para ejecutar directamente las medidas cautelares que hayan ordenado. En este caso las partes deberán recurrir a los jueces ordinarios para solicitar su ejecución ${ }^{74}$. El artículo 363 del COGEP establece que los jueces ordinarios "ejecutarán las providencias preventivas ordenadas por los tribunales de arbitraje nacionales o internacionales"75. Es claro de esta norma que, aunque éstas no constituya títulos de ejecución, las medidas cautelares, provengan de un arbitraje doméstico o internacional, deben ser ejecutadas por los jueces civiles, en ambos casos sin que el requerido pueda oponerse a la medida y, en el último de los casos, sin la necesidad de un proceso de homologación previo. Por la ubicación de la disposición dentro del código, no queda duda que el procedimiento que se debe seguir para la ejecución de las medidas cautelares -insistimos, aunque no sean títulos de ejecución- es aquel señalado en el Libro V "Ejecución” del COGEP. Este procedimiento será analizado más adelante, conjuntamente con la ejecución de laudos arbitrales.

71. COGEP, Art. 133, Nota 2.

72. "Los árbitros podrán dictar medidas cautelares, de acuerdo con las normas del [COGEP] o las que se consideren necesarias para cada caso, para asegurar los bienes materia del proceso o para garantizar el resultado de éste". LAM, Art. 9, Nota 10.

73. LAM, Art. 9, párrafo tercero, Nota 10. Ver además, A. PONCE MARTínEZ, "Notas sobre medidas provisionales en arbitraje con especial referencia al caso City Oriente contra la República del Ecuador", Revista Peruana de Arbitraje, No. 9, 2009, pp. 13-15. Este poder es un claro ejemplo de que en el Ecuador los árbitros sí tienen ius imperium, aunque éste esté limitado únicamente a la ejecución de medidas cautelares y bajo la condición de que las partes así lo hayan acordado.

74. LAM, Art. 9, último párrafo, Nota 10.

75. COGEP, Art. 363, último párrafo, Nota 2. 


\subsection{Homologación de laudos internacionales ${ }^{76}$}

Hasta el momento de la expedición del COGEP, el artículo 42 de la LAM establecía que "[1]os laudos dictados dentro de un procedimiento de arbitraje internacional, tendrán los mismos efectos y serán ejecutados de la misma forma que los laudos dictados en un procedimiento de arbitraje nacional"77. Esta disposición generó un interesante debate en el foro ecuatoriano sobre si era o no necesario realizar un procedimiento de homologación previa la ejecución de un laudo internacional ${ }^{78}$. La mayoría de la doctrina -apoyada en la jurisprudencia local ${ }^{79}$ - se inclinaba a considerar que, en virtud de este artículo, los laudos arbitrales internacionales, al asimilarse a los laudos nacionales, no necesitaban de homologación y debían ser ejecutados conforme lo dispone el artículo 32 de la LAM $^{80}$. Con la expedición del COGEP esta situación ha cambiado drásticamente, primero, porque deroga el párrafo final del artículo 42 de la LAM citado previamente, y, segundo, porque se implementa un nuevo procedimiento para la homologación de laudos internacionales, sin cuyo cumplimiento, un laudo internacional no podrá ser ejecutado en el Ecuador. Al parecer, este nuevo procedimiento de dos etapas implica un retroceso en la materia y quizás es el caballo de Troya que el COGEP trae al arbitraje.

76. Como se mencionó en la sección 5.2.1, este procedimiento no se aplica para la ejecución de medidas cautelares ordenadas por tribunales de arbitraje internacional.

77. LAM, Art. 42, Nota 10. Esta disposición fue derogada por la disposición derogatoria Décimotercera del COGEP.

78. Ver S. ANDRADE UBIDIA, "En torno al tema del reconocimiento y ejecución de sentencias extranjeras y laudos internacionales", Foro: Revista de Derecho, No. 6, 2006, pp. 59-93; X. ANDRADE CADENA, "Reconocimiento y ejecución de laudos extranjeros en Ecuador: un camino inexplorado", Revista internacional de arbitraje, No. 8, 2008, pp. 146-193; A. GALINDO CARDONA, "Origen y desarrollo de la Solución Alternativa de Conflictos en Ecuador”, Iuris Dictio, No. 4, 2011, 123-128; A. C. DONOSO BUSTAMANTE, El reconocimiento de la extraterritorialidad de los laudos arbitrales extranjeros y su procedimiento de ejecución, en la práctica procesal ecuatoriana, Repertorio de Tesis de la Universidad Andina Simón Bolívar, 2008, <http://goo.gl/iX7QvQ>; R. ILLINGWORTH CABANILLA, Los laudos arbitrales nacionales e internacionales: su contenido, reconocimiento y ejecución, Conferencia Interamericana de Arbitraje Comercial de la Comisión Interamericana de Arbitraje Comercial CIAC; X. ANDRADE CADENA y J. M. MARChÁN, "El arbitraje comercial internacional en Ecuador: marco legal y jurisprudencial”, en C. CONEJERO ROOS et al., El arbitraje comercial internacional en Iberoamérica: marco legal y jurisprudencial, La Ley-Wolter Kluwer, 2009, pp. 319-248; E. NEIRA OrELlANA, "Arbitrabilidad, Convención sobre el Reconocimiento y Ejecución de Sentencias Arbitrales y Legislación Ecuatoriana”, en C. SoTo (Dir.), Arbitraje Comercial y Arbitraje de Inversiones: Convención de Nueva York de 1958 Reconocimiento y Ejecución de Sentencias Arbitrales Extranjeras, Instituto Peruano de Arbitraje, 2009, pp. 151-174; F. ENDARA y A. GALINDO CARDONA, "Ecuador", en O. GARCÍA-Bolívar y H. OTERo (Ed.), Recognition and Enforcement of International Commercial Arbitral Awards in Latin America, Koninklijke Brill NV, 2015, pp. 121-136.

79. Juzgado Vigésimo Tercero de lo Civil de Pichincha, Doug W. Cannaday c. Glenn Allan Good y Hampton Court Resources Ecuador S.A., Causa No. 812 (2006), Auto de 8/2/2008; Juzgado Octavo de lo Civil del Guayas, Daewoo Electronics America, Inc. c. Expocarga S.A., Causa No. 469 (2009) Auto de 26/10/2009.

80. LAM, Art. 32, Nota 10. 
No es el objetivo del presente artículo analizar in extensum el procedimiento de homologación de laudos internacionales establecidos en el nuevo COGEP, pero sí revisaremos la normativa relevante y trataremos de identificar algunos de los problemas que se pueden evidenciar en el nuevo articulado.

El artículo 102 del COGEP establece que la competencia para conocer la homologación de laudos arbitrales corresponderá a la sala especializada de la Corte Provincial del domicilio del requerido ${ }^{81}$, la que deberá verificar que el laudo arbitral expedido en el extranjero cumpla con los siguientes requisitos ${ }^{82}$ :

1. Que tengan las formalidades externas necesarias para ser considerados auténticos en el Estado de origen.

2. Que la sentencia pasó en autoridad de cosa juzgada conforme con las leyes del país en donde fue dictada y la documentación anexa necesaria está debidamente legalizada.

3. Que de ser el caso, estén traducidos.

4. Que se acredite con las piezas procesales y certificaciones pertinentes que la parte demandada fue legalmente notificada y que se haya asegurado la debida defensa de las partes.

5. Que la solicitud indique el lugar de citación de la persona natural o jurídica contra quien se quiere hacer valer la resolución expedida en el extranjero.

El primer requisito no trae mayor inconveniente. Bastaría con señalar cuáles son los requisitos formales que debe cumplir un laudo bajo la legislación donde fue proferido y evidenciar que el laudo cumple con tales requisitos. $\mathrm{Si}$ ningún requisito formal le es impuesto al laudo, la causal no tiene relevancia alguna. El tercer requisito tampoco trae mayor complejidad y simplemente implica cumplir con lo dispuesto en el artículo 200 del COGEP ${ }^{83}$. Lo mismo con respecto del quinto requisito. Por otro lado, los requisitos segundo y cuarto pueden traer ciertas complicaciones por lo que se justifica su análisis.

81. COGEP, Art. 102, Nota 2.

82. COGEP, Art. 104, Nota 2.

83. COGEP, Art. 104, Nota 2. 
El segundo requisito merece dos precisiones. Primero, el requisito según el cual un laudo debe haber pasado "en autoridad de cosa juzgada conforme con las leyes del país en donde fue dictad[o]", al igual que en el primer requisito, requiere simplemente de una constatación sobre si un laudo tiene efecto de cosa juzgada conforme la legislación del país de origen. En este sentido, no es necesario que el solicitante presente una certificación formal del cumplimiento de esos requisitos pues, de lo contrario, esto implicaría un doble exequátur cuya exigencia fue eliminada por la Convención de Nueva York $(\mathrm{CNY})^{84}$. Segundo, bajo este requisito, en el Ecuador no sería posible ejecutar laudos parciales ni laudos interinos que no sean finales, así como tampoco sería posible ejecutar un laudo internacional que fue anulado en la sede, tomando, en este último caso, una postura clara sobre este tema altamente discutido en el foro internacional ${ }^{85}$. Queda aún la duda de si sería o no posible ejecutar una decisión ordenada por un árbitro de emergencia. Esto dependerá ulteriormente de si el reglamento de arbitraje bajo el cual se instituyó el procedimiento de emergencia le da la calidad de laudo final a la resolución del árbitro de emergencia o de si podría considerársele, para efectos del COGEP, como una "providencia preventiva" ordenada por un tribunal internacional. Tal vez responder afirmativamente a la segunda cuestión daría más seguridad y eficacia a tales resoluciones, y aportaría a la construcción de un sistema más favorable al arbitraje internacional.

84. Convención Sobre el Reconocimiento y la Ejecución de las Sentencias Arbitrales Extranjeras, 1958, <http:// goo.gl/2xvQfY>.

85. Para entender el contexto y la relevancia de la reforma planteada en el COGEP, vamos a intentar resumir el debate. La discusión gira en torno a la interpretación de la CNY -y por obvias razones de la Convención Interamericana sobre Arbitraje Comercial Internacional (CP), 1975, <http://goo.gl/VGtJMH >- con respecto de la facultad que tiene un juzgador para reconocer y ejecutar un laudo cuando éste ha sido anulado en su país de origen. Para explicar el problema escogeremos el debate mantenido por dos reconocidas autoridades en la materia, A. J. VAN DEn Berg y J. PAulsson. Según PAulsson (J. PAulsson, "Enforcing Arbitral Awards Notwithstanding A Local Standard Annulment (LSA)", The ICC International Court of Arbitration Bulletin, Vol. 9 (1), 1998, pp. 14-31), como consecuencia de la deslocalización del arbitraje internacional, un laudo emitido en un país cuyos efectos se desplegarán en otro lugar no se incorpora al sistema jurídico de su sede, por lo que no está sujeto a los estándares locales para su validez. Si éste cumple con los estándares internacionales para que proceda su ejecución, independientemente de si es anulado en la jurisdicción donde fue proferido, el laudo arbitral podría ser ejecutado en cualquier otro lugar. Por el contrario, para VAN DEN BERG (A. J. VAN DEN BERG, "Enforcement of Annulled Awards?", The ICC International Court of Arbitration Bulletin, Vol. 9 (2), 1998, pp. 15-21) la intención de la CNY en este respecto es el de incorporar el laudo al ordenamiento jurídico donde fue proferido pues es producto de la lex loci arbitri y consecuentemente está afectado por el poder que esta otorga a las cortes del lugar sede del arbitraje. Así, en aras de obtener seguridad jurídica, una vez que un laudo ha sido anulado por el juez de la sede, éste deja de existir y no debería poder ser ejecutado en ninguna otra jurisdicción -ex nihilo nil fit-. Al amparo de la nueva normativa, el Ecuador se ha suscrito a esta última tendencia. 
El cuarto requisito es el más controversial y habrá quien pueda afirmar que el mismo impone un requisito aparentemente más gravoso que los requeridos por la CNY. Nos referimos al requisito que el solicitante pruebe que se ha respetado el derecho al debido proceso de la parte demandada. Además de imponer la carga de la prueba al solicitante, esta disposición generaría una carga extremadamente gravosa, por varios motivos. Primero, qué derechos comprenden el derecho a la defensa de una parte, ¿aquellos comprendidos en la legislación de la sede?, ¿aquellos enunciados en la constitución del Ecuador? Segundo, ciertos derechos son virtualmente imposibles de probar pues solo se evidencian cuando son vulnerados. Tercero, este requisito parecería imponer al solicitante la prueba de un hecho negativo -que no se haya vulnerado el derecho a la debida defensa de la contraparte- $y$, ciertamente, es jurídicamente imposible probar un hecho negativo. Cuarto, lo que seguramente sucederá en la práctica es que la parte solicitante adjuntará copias de todo el proceso, lo que conlleva una carga onerosa - pues pueden ser miles y miles de copias que deben ser obtenidas en el extranjero, que deben traducirse- (si es el caso), -legalizarse y luego traerse al Ecuador. Además esto tendría como consecuencia que el expediente de homologación se llene de copias innecesarias, lo que implica a su vez también un mayor costo para la administración de justicia.

Es evidente que la interpretación de este requisito debe, en la práctica, minimizar el gravamen que podría causarse a un solicitante. Lo adecuado sería que, en virtud de lo dispuesto en el artículo 425 de la Constitución del Ecuador ${ }^{86}$, las cortes no apliquen este requisito de encontrar que es contrario a la CNY. De no ser este el caso, uno podría pensar que, como otra alternativa, una parte podría simplemente presentar copias de las notificaciones de solicitud e inicio del arbitraje y una certificación del secretario del tribunal o algún oficial de la institución que administra el arbitraje, estableciendo que se ha garantizado la debida defensa de las partes ${ }^{87}$. Otra

86. "Art. 425.- El orden jerárquico de aplicación de las normas será el siguiente: La Constitución; los tratados y convenios internacionales; las leyes orgánicas; las leyes ordinarias; las normas regionales y las ordenanzas distritales; los decretos y reglamentos; las ordenanzas; los acuerdos y las resoluciones; y los demás actos y decisiones de los poderes públicos. En caso de conflicto entre normas de distinta jerarquía, la Corte Constitucional, las juezas y jueces, autoridades administrativas y servidoras y servidores públicos, lo resolverán mediante la aplicación de la norma jerárquica superior. [...]”. Constitución del Ecuador, Art. 425, Nota 36. (Énfasis añadido)

87. Esto podría traer complicaciones inherentes. Podría ser muy dificil obterner dicho certificado de alguna autoridad del centro o del secretario arbitral. Más aún, sería mucho más complicado conseguirlo si el caso está en proceso de anulación en la sede o su ejecución ha sido negada en otras jurisdicciones. 
forma de cumplir con este requisito sería adjuntar, de existir, una resolución que rechaza la nulidad del laudo por estos motivos ${ }^{88}$.

Este mismo artículo nos trae también, en un lenguaje algo confuso, un último requisito que la Corte debe verificar antes de dar inicio al proceso de homologación. El párrafo final del artículo 104 del COGEP establece que:

Para efectos del reconocimiento de las sentencias y laudos arbitrales en contra del Estado, por no tratarse de asuntos comerciales, deberá además demostrarse que no contrarían las disposiciones de la Constitución y la ley, y que estén arregladas a los tratados y convenios internacionales vigentes. A falta de tratados y convenios internacionales se cumplirán si constan en el exhorto respectivo o la ley nacional del país de origen reconoce su eficacia y valide $z^{89}$.

Primero, este requisito parte de un error conceptual: todo laudo dictado en contra de un Estado tiene como objeto de la disputa una materia no comercial. Los Estados mantienen relaciones comerciales que más tarde pueden ser objeto de un proceso arbitral, e.g., la compraventa de un vehículo para un sistema de transporte público. En este sentido, con el objeto de contribuir al desarrollo del arbitraje en el Ecuador, podría entenderse que cuando se trate de laudos cuya materia no sea comercial -e.g. una disputa en materia de inversiones bajo el Derecho internacional público-, el solicitante deberá probar que dicho arbitraje está permitido bajo la legislación ecuatoriana -incluidos los tratados internacionales ratificados por el Ecuador- y que su laudo fue proferido con arreglo a las disposiciones aplicables al mismo. No creemos que el solicitante deba probar que el laudo se encuentra en conformidad con la legislación ecuatoriana pues esto podría ser un motivo de oposición invocado por la parte que se opone a la ejecución.

En cuanto al procedimiento de homologación, el artículo 105 del COGEP $^{90}$ establece que, una vez que se haya cumplido con lo establecido en el artículo 104 del COGEP, se citará a la persona contra quien el laudo se

88. Un problema sería es el tiempo que se tardaría en obtener una sentencia final en la que se rechace la nulidad del laudo, e.g., en Francia el proceso puede llegar hasta la Corte de Casación para resolver en última instancia la nulidad del laudo. Otra dificultad que se presentaría es que esta sentecia también debería ser reconocida y homologada para que surta plenos efectos en el Ecuador.

89. COGEP, Art. 104, Nota 2.

90. COGEP, Art. 104, Nota 2. 
intenta hacer valer, quien tendrá cinco días para presentar y probar su oposición. Toda vez que el artículo no prevé cuales son las razones por las cuales el requerido se puede oponer a la homologación del laudo, es claro que, por su lenguaje vinculante -"sólo se podrá denegar"- y por ser parte del ordenamiento jurídico ecuatoriano ${ }^{91}$, se debe aplicar lo dispuesto en el artículo 5 del la $\mathrm{CNY}^{92}$-o 5 de la $\mathrm{CP}$ - que establece:

1. Solo se podrá denegar el reconocimiento y la ejecución de (un laudo), a instancia de la parte contra la cual es invocada, si esta parte prueba ante la autoridad competente del país en que se pide el reconocimiento y la ejecución:

a) Que las partes en el acuerdo a que se refiere el artículo 2 estaban sujetas a alguna incapacidad en virtud de la Ley que le es aplicable o que dicho acuerdo no es válido en virtud de la Ley a que las partes lo han sometido, o si nada se hubiera indicado a este respecto, en virtud de la Ley del país en que se haya dictado la sentencia; o

b) Que la parte contra la cual se invoca la sentencia arbitral no ha sido debidamente notificada de la designación del arbitro o del procedimiento de arbitraje o no ha podido, por cualquier otra razón, hacer valer sus medios de defensa; o

c) Que la sentencia se refiere a una diferencia no prevista en el compromiso o no comprendida en las disposiciones de la cláusula compromisario, o contiene decisiones que exceden de los términos del compromiso o de la cláusula compromisaria; no obstante, si las disposiciones de la sentencia que se refieren a las cuestiones sometidas al arbitraje pueden separarse de las que no han sido sometidas al arbitraje, se podrá dar reconocimiento y ejecución a las primeras; $o$

91. “Art. 425.- El orden jerárquico de aplicación de las normas será el siguiente: La Constitución; los tratados y convenios internacionales; las leyes orgánicas; las leyes ordinarias; las normas regionales y las ordenanzas distritales; los decretos y reglamentos; las ordenanzas; los acuerdos y las resoluciones; y los demás actos y decisiones de los poderes públicos". Constitución del Ecuador, Art. 425, Nota 36. "Art. 2.- En todas las actividades procesales se aplicarán los principios previstos en la Constitución de la República, en los instrumentos internacionales de derechos humanos, en los instrumentos internacionales ratificados por el Estado, en el Código Orgánico de la Función Judicial y los desarrollados en este Código". COGEP, Art. 2, Nota 2.

92. CNY, Art. V, Nota 78. 
d) Que la constitución del tribunal arbitral o el procedimiento arbitral no se han ajustado al acuerdo celebrado entre las partes o, en defecto de tal acuerdo, que la constitución del tribunal arbitral o el procedimiento arbitral no se han ajustado a la Ley del país donde se ha efectuado el arbitraje; $o$

e) Que la sentencia no es aun obligatoria para las partes o ha sido anulada o suspendida por una autoridad competente del país en que, o conforme a cuya Ley, ha sido dictada esa sentencia.

2. También se podrá denegar el reconocimiento y la ejecución de una sentencia arbitral si la autoridad competente del país en que se pide el reconocimiento y la ejecución comprueba:

a) Que, según la Ley de ese país, el objeto de la diferencia no es susceptible de solución por vía de arbitraje; o

b) Que el reconocimiento o la ejecución de la sentencia serían contrarios al orden público de ese país.

Finalmente, si el requerido no presentó oposición o si la presentó, pero la complejidad de la causa no amerita una audiencia, la Corte Provincial respectiva deberá resolver la solicitud en el término de treinta días contados desde que se citó al requerido. En el caso que éste haya presentado oposición y la complejidad de la causa lo amerite, la Corte Provincial convocará una audiencia en el término máximo de veinte días contados desde la presentación de la oposición.

Una última inquietud queda aún por ser respondida: ¿podría una parte solicitar una medida cautelar, sea antes o conjuntamente con la homologación, con el objetivo de asegurar el pago futuro del laudo? Un primer obstáculo podría encontrarse en el artículo 106 del COGEP que establece que "[l]a parte que dentro de un proceso, pretenda hacer valer los efectos probatorios de una sentencia, laudo arbitral o acta de mediación expedidos en el extranjero, previamente deberá homologarlos en la forma prevista en [el COGEP]"93. Pese a lo anterior, uno bien podría presentar el laudo como una evidencia de apariencia de buen derecho y simultáneamente probar, de manera preliminar, la existencia del crédito con otros documentos según lo requiere el artículo 125 del COGEP.

93. COGEP, Art. 106, Nota 2. 


\subsection{Ejecución de laudos arbitrales}

Este es, a nuestro criterio, el último escenario donde el COGEP tiene una relación con el resultado del procedimiento arbitral: el laudo. Según el artículo 362 del COGEP, ejecución es "el conjunto de actos procesales para hacer cumplir las obligaciones contenidas en un título de ejecución"94. De conformidad con el artículo 363 del COGEP ${ }^{95}$, son títulos de ejecución los siguientes:

1. La sentencia ejecutoriada.

2. El laudo arbitral.

3. El acta de mediación.

4. El contrato prendario y de reserva de dominio.

5. La sentencia, el laudo arbitral o el acta de mediación expedidos en el extranjero, homologados conforme con las regla de este Código.

6. Las actas transaccionales.

7. Los demás que establezca la ley.

El COGEP regula de manera individual la ejecución de las obligaciones de dar una especie o cuerpo cierto ${ }^{96}$, la ejecución de las obligaciones de dar dinero o bienes de género ${ }^{97}$, la ejecución de las obligaciones de hacer ${ }^{98}$, y la ejecución de las obligaciones de no hacer ${ }^{99}$. Una vez que el juez haya aceptado a trámite la solicitud de ejecución, el juez debe designar un perito para la liquidación de capital, intereses y $\operatorname{costas}^{100}$. Recibida la liquidación, el juez expedirá el mandamiento de ejecución, otorgando al ejecutado un término de cinco días para que cumpla con la obligación ${ }^{101}$. El ejecutado solo podrá oponerse a la ejecución por una de las siguientes circunstancias: [1] pago o dación en pago, [2] transacción, [3] remisión, [4] novación, [5] confusión, [6] compensación, [7] pérdida o destrucción de la cosa debida. Si el ejecutado no cumple la obligación en el plazo concedido por el juez, se procederá con la ejecución forzosa de la obligación.

\footnotetext{
94. COGEP, Art. 362, Nota 2

95. COGEP, Art. 363, Nota 2.

96. COGEP, Art. 366, Nota 2.

97. COGEP, Art. 367, Nota 2.

98. COGEP, Art. 368, Nota 2.

99. COGEP, Art. 369, Nota 2.

100. COGEP, Art. 371, Nota 2.

101. COGEP, Art. 372, Nota 2.
} 


\section{A manera de conclusiones}

Como se ha visto en el transcurso de este trabajo, el procedimiento arbitral es autónomo y se rige por la voluntad de las partes, por lo que el COGEP no se aplica directamente al arbitraje, salvo en aquellos casos en los que la LAM hace expresa referencia al mismo; sin embargo, el COGEP también establece algunos procedimientos que sirven de auxilio jurisdiccional a los procedimientos arbitrales.

Dentro de aquellas disposiciones del COGEP que, por expreso mandato de la LAM, le son aplicables a los procedimientos arbitrales tenemos a los requisitos que deben observar la demanda, contestación a la demanda, reconvención y contestación a la misma; y las causales y procedimiento de excusa y recusación de los árbitros. Por un lado, con respecto a los requisitos que debe contener la demanda, contestación a la demanda, reconvención y contestación a la misma, la normativa no representa un mayor cambio con respecto a las disposiciones del CPC. Tal vez la mayor innovación en este tema es el requisito de adjuntar a estos documentos los peritajes de parte. Por otro lado, sobre las causales de excusa y recusación de los árbitros, en términos generales, parece ser que la simple y pura adopción de las causales previstas en el COGEP al arbitraje es, en ciertos casos, inadecuada y deben pasar por un proceso de adaptación al proceso arbitral.

Dentro de los procesos auxiliares a los procedimientos arbitrales debemos destacar un avance y un retroceso en materia arbitral. Sobre el primer punto, es bienvenida la disposición por la cual los jueces ordinarios deben ejecutar de manera directa las medidas cautelares de tribunales de arbitraje local e internacional. Esto implica que los jueces deben ejecutar estas órdenes arbitrales sin la posibilidad de revisar el fondo ni la forma de la medida, sin que se requiera previa homologación ni que el ejecutado tenga la posibilidad de oponerse a la misma. El retroceso vino de la mano del nuevo procedimiento -en dos etapas- para el reconocimiento y ejecución de laudos internacionales. El nuevo proceso no es claro, simple e impone en el solicitante la carga de probar el efecto de res iudicata y de la legalidad y compatibilidad con el ordenamiento jurídico. Podría argumentarse que esto hace que el procedimiento de reconocimiento de laudos internacionales sea más gravoso que aquel requerido por la CNY y la CP. De considerarse así, en función de lo dispuesto por el artículo 425 de la 
Constitución del Ecuador y el artículo 2 del COGEP, los juzgadores deberían aplicar directamente las disposiciones de los instrumentos internacionales en materia arbitral de los que el Ecuador es parte, descartando aquellas normas del COGEP que podrían contravenir las disposiciones de la CNY y la CP.

Finalmente, vale la pena advertir que las conclusiones y análisis realizados en el presente trabajo son reflexiones preliminares y no pretenden ser concluyentes. Mucho camino queda por recorrer para ver cómo los centros de arbitraje, los árbitros y los jueces, cada uno en la esfera de sus facultades, desarrollan e interpretan estas disposiciones. Solo entonces podremos saber si el COGEP se convierte, efectivamente, en un caballo de Troya para el arbitraje o en la promesa de un Código que "[...] fomenta la inmediación, la transparencia, la eficacia, la economía procesal, la celeridad, la igualdad ante la ley, la imparcialidad, la simplificación, la uniformidad. Principalmente, precautela los derechos y garantías constitucionales y procesales" 102 . 